\title{
A New Era of Clinical Dopamine Transporter Imaging Using ${ }^{123}$ I-FP-CIT*
}

\author{
Eunkyung Park
}

Department of Nuclear Medicine, School of Medicine and Biomedical Sciences, University at Buffalo, State University of New York, Buffalo, New York

\begin{abstract}
123/-labeled $2 \beta$-carbomethoxy-3 $\beta$-(4-iodophenyl)- $N$-(3-fluoropropyl)nortropane (123I-FP-CIT) was approved for clinical use in 2011 by the Food and Drug Administration. ${ }^{123}$ I-FP-CIT is a radioligand for brain dopamine transporter (DAT) imaging that is useful for the differential diagnosis of Parkinson disease (PD) and other diseases that mimic PD. The sensitivity and specificity of ${ }^{123} \mathrm{I}-\mathrm{FP}-\mathrm{CIT}$ SPECT for PD diagnosis are more than $90 \%$ and equivalent to those of other DAT SPECT methods. In the near future, the clinical indications of DAT imaging are expected to be broadened; for example, including treatment response assessment, disease progression monitoring, and early diagnosis of premotor PD in each individual patient.
\end{abstract}

Key Words: dopamine transporter; Parkinson disease; FP-CIT; ioflupane; DaTSCAN

J Nucl Med Technol 2012; 40:222-228

DOI: 10.2967/jnmt.112.111617

$\mathbf{P}$

arkinson disease (PD) is the second most common neurodegenerative disorder after Alzheimer dementia (1). Studies suggest that PD affects at least 500,000 people in the United States (2), and 1\%-2\% of people over 65 y old have PD (3). Approximately 50,000 new cases are diagnosed each year (4). The financial and public health impact of this disease is expected to increase as the average age of the population increases (2).

The classic motor symptoms of PD are tremor of a limb, rigid limbs, slow movement, and balance problems. The tremor often begins insidiously on one side of the body and spreads to the other side with a slowly deteriorating course $(5,6)$. These symptoms are attributed mostly to dopamine deficit, secondary to progressive loss of dopamine-secreting neurons projecting from the substantia nigra to the striatum

\footnotetext{
Received Jul. 23, 2012; revision accepted Oct. 10, 2012.

For correspondence or reprints contact: Eunkyung Park, PET Center, Department of Diagnostic Radiology, School of Medicine, Yale University, 801 Howard Ave., New Haven, CT 06520-8048.

E-mail: angela.park@yale.edu

Published online Nov. 16, 2012.

*NOTE: FOR CE CREDIT, YOU CAN ACCESS THIS ACTIVITY THROUGH THE SNMMI WEB SITE (http://www.snmmi.org/ce_online) THROUGH DECEMBER 2014.

COPYRIGHT (C) 2012 by the Society of Nuclear Medicine and Molecular Imaging, Inc.
}

$(7,8)$. Dopamine is a neurotransmitter that regulates movement, and therefore the lack of dopamine produces abnormal movement. The dopamine transporter (DAT) controls the intensity and duration of dopaminergic neurotransmission by rapid reuptake of dopamine into presynaptic terminals (9-11). DAT density correlates with the density of dopaminergic neurons and is used as an imaging biomarker for diagnosing PD.

\section{A NEW ERA OF CLINICAL DOPAMINE TRANSPORTER IMAGING USING ${ }^{123}$ |-LABELED 2 $\beta$-CARBOMETHOXY- 3及-(4-IODOPHENYL)- $N$-(3-FLUOROPROPYL) NORTROPANE (123I-FP-CIT)}

The Food and Drug Administration (FDA) approved the clinical use of ${ }^{123}$ I-FP-CIT (international nonproprietary name ioflupane, brand name DaTSCAN [GE Healthcare]) in January 2011 (12). ${ }^{123}$ I-FP-CIT is indicated for the visualization of the presynaptic DAT distribution within the striatum by SPECT in patients with suspected Parkinsonian syndromes. Striatal uptake of ${ }^{123}$ I-FP-CIT is reduced in patients with PD, which is a motor system disorder resulting from dopaminergic neurodegeneration.

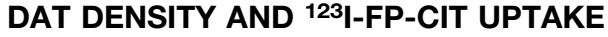

DAT is a sodium chloride-dependent transmembrane protein on the presynaptic dopaminergic nerve terminal that controls dopamine levels by active reuptake of dopamine from the synaptic cleft after its interaction with the postsynaptic receptor $(11,13)$. Striatal ${ }^{123}$ I-FP-CIT uptake is correlated with DAT density (14). With dopaminergic neurodegeneration, DAT density decreases and therefore striatal ${ }^{123}$ I-FP-CIT uptake is reduced on DAT imaging.

\section{WHY DO WE IMAGE STRIATAL DAT DENSITY?}

Why do we image DAT density in the striatum when the major pathology of PD is in the neurodegeneration of dopaminergic cells in the substantia nigra? The reason is that DAT is specific to dopaminergic neurons and best correlates with the density of dopaminergic neurons. Imaging other aspects of dopaminergic neuronal function-for example, dopamine synthesis rate or dopamine receptor density — can evaluate dopaminergic neurodegeneration. Indeed, there are many radioligands available for imaging these other aspects of dopaminergic neuronal function. However, dopamine 
synthesis imaging has some drawbacks, and postsynaptic dopamine receptor imaging does not help in diagnosing PD patients because PD pathology is on the presynaptic side. ${ }^{18} \mathrm{~F}-\mathrm{L}-6$-fluoro-3,4-dihydroxyphenylalanine $\left({ }^{18} \mathrm{~F}-\mathrm{DOPA}\right)$ is a representative radioligand for dopamine synthesis and reflects dopaminergic as well as noradrenergic neuronal function. ${ }^{18} \mathrm{~F}$-DOPA imaging involves multiple steps including the uptake and conversion of fluorodopa to fluorodopamine (15). ${ }^{18} \mathrm{~F}$-DOPA uptake is not a direct measure of nigral cell count (15). Furthermore, compensatory upregulatory changes of dopamine synthesis rate might occur in $\mathrm{PD}$, hindering accurate measurement (15). DATs are known to be downregulated in PD patients as an early response to decreased synaptic dopamine concentration (16). DAT imaging might be a more sensitive indicator of dopaminergic degeneration than ${ }^{18} \mathrm{~F}-\mathrm{DOPA}$ (17).

\section{RADIOLIGANDS FOR DAT IMAGING AND THEIR CLINICAL AVAILABILITY}

There are several radioligands for DAT imaging. Among DAT imaging methods, SPECT using ${ }^{123}$ I- $\beta$-CIT, ${ }^{123}$ I-FPCIT, or ${ }^{99 \mathrm{~m}} \mathrm{Tc}-\mathrm{TRODAT}-1$ has been most widely used and approved for clinical use in different countries. ${ }^{123}$ I-FP-CIT is not the first of its kind but has recently become the first and only U.S. FDA-approved radioligand for DAT imaging for clinical purposes. This newly approved radioligand actually was already authorized for clinical use in July 2000 in Europe (18), for the differential diagnosis of patients with clinically uncertain Parkinsonian syndrome. Its diagnostic indication expanded for the differential diagnosis of probable dementia with Lewy bodies (DLB) from Alzheimer disease in July 2006 (19). In addition to Europe, Korea recently approved ${ }^{123}$ I-FP-CIT for clinical use in 2011 (20). More than 300,000 people in 34 countries have undergone ${ }^{123}$ I-FP-CIT brain SPECT as of 2011 (21). Table 1 shows the approval year of several representative DAT imaging radioligands for clinical use. In Europe, ${ }^{123}$ I- $\beta$-CIT is also available for routine clinical use. Another radioligand for DAT imaging, ${ }^{99 m}$ Tc-TRODAT-1, was approved for routine clinical use in Taiwan in 2005 but was reported to be underutilized for bureaucratic and economic reasons despite the advantageous imaging properties of technetium (22). Several DAT radioligands for PET have been developed. ${ }^{18} \mathrm{~F}$-FP-CIT is available for clinical use in Korea; its first approval anywhere in the world was by the Korean FDA in 2008 (23). A newer synthesis method published in 2007 contributed to the clinical use of ${ }^{18} \mathrm{~F}-\mathrm{FP}$-CIT by significantly improving the radiochemical yield (24).

\section{CHARACTERISTICS OF ${ }^{123}$ I-FP-CIT}

${ }^{123} \mathrm{I}$-FP-CIT is a radioiodinated cocaine analog. The physical half-life of ${ }^{123} \mathrm{I}$ is $13 \mathrm{~h}$, and the major $\gamma$-ray from ${ }^{123} \mathrm{I}$ decay has an energy of $159 \mathrm{keV}$. ${ }^{123}$ I-FP-CIT is classified as a schedule II controlled substance under the Controlled Substances Act in the United States. Registration with the Drug Enforcement Agency is required to order it, and appropriate
TABLE 1

Approval Year for Clinical Use of Radioligands for DAT Imaging

\begin{tabular}{|c|c|c|}
\hline Radioligand & United States & Elsewhere \\
\hline $\begin{array}{c}{ }^{123} \text { I- } \beta \text {-CIT (DOPASCAN; MAP } \\
\text { Medical Technologies Oy) }\end{array}$ & - & Europe*, Japan* \\
\hline 123I-FP-CIT (DaTSCAN) & 2011 & $\begin{array}{r}2000 \text { in Europe, } \\
2011 \text { in Korea }\end{array}$ \\
\hline${ }^{18} \mathrm{~F}-\mathrm{FP}-\mathrm{CIT}$ & - & 2008 in Korea \\
\hline 99mTc-TRODAT-1 & - & 2005 in Taiwan \\
\hline
\end{tabular}

physician licensure and clinic registration are mandatory (16). The recommended dosage of ${ }^{123}$ I-FP-CIT is 111-185 MBq (3-5 mCi), typically $185 \mathrm{MBq}(5 \mathrm{mCi})$. The effective dose of a single ${ }^{123}$ I-FP-CIT brain SPECT scan is estimated to be $2.3-4.4 \mathrm{mSv}$, which is similar to a chest CT dose (16). ${ }^{123}$ I-FP-CIT is taken up rapidly in the human striatum, and
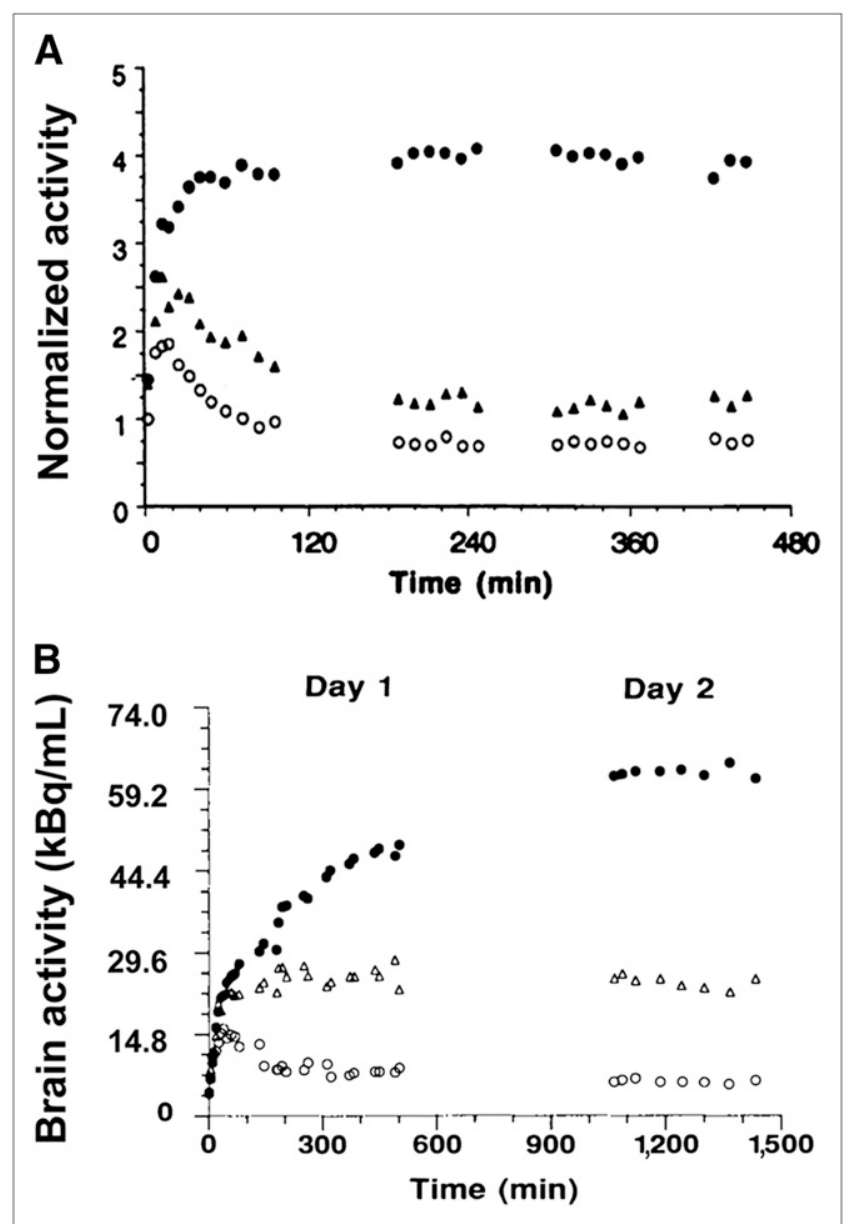

FIGURE 1. Faster kinetics of ${ }^{123} \mathrm{I}-\mathrm{FP}-\mathrm{CIT}$. In human striatum, ${ }^{123}$ I-FP-CIT (A) is taken up more rapidly than ${ }^{123}$ I- $\beta$-CIT (B). Practical clinical advantage of fast kinetics of ${ }^{123}$ I-FP-CIT is that patients can be scanned on same day 3-6 h after injection. (Panel B reprinted with permission of (26).) 
a stable level of striatal radioactivity (equilibrium of specific to nonspecific uptake of radioactivity) is achieved around $4 \mathrm{~h}$ after injection (Fig. 1A) (25). ${ }^{123}$ I- $\beta$-CIT was developed earlier than ${ }^{123} \mathrm{I}$-FP-CIT and is the first cocaine analog radioligand that came out. However, ${ }^{123}$ I- $\beta$-CIT slowly reaches a stable level of striatal radioactivity at 20-30 h after injection (Fig. 1B) (26), meaning that patients with difficulty in moving around need to visit the hospital for 2 $\mathrm{d}$ for injection and imaging procedures. Because of its faster kinetics, ${ }^{123}$ I-FP-CIT was a breakthrough for outpatient procedures. ${ }^{123}$ I-FP-CIT allows patients to be scanned on the same day at 3-6 h after injection. Another advantage of ${ }^{123} \mathrm{I}-\mathrm{FP}-\mathrm{CIT}$ is that it has higher selectivity for DAT than ${ }^{123} \mathrm{I}-\beta$-CIT $(25,27)$. However, nonspecific uptake in the background regions is higher with ${ }^{123}$ I-FP-CIT.

\section{DAT IMAGING PROTOCOL USING ${ }^{123}$ I-FP-CIT}

Images are usually obtained at $4 \mathrm{~h}$ after the injection of ${ }^{123} \mathrm{I}-\mathrm{FP}-\mathrm{CIT}$, but they can be obtained 3-6 $\mathrm{h}$ after injection. The oral administration of potassium perchlorate or potassium iodide solution, or Lugol solution, is recommended before the ${ }^{123}$ I-FP-CIT injection, to block thyroid uptake of free radioactive iodide. In Europe, where ${ }^{123} \mathrm{I}$-FP-CIT has been used for a decade, Lugol solution is often not administered and some clinicians believe that it may not be necessary. Fasting is unnecessary, and patients do not need to be kept in a dim or quiet environment. Antiparkinsonian drugs including L-dopa, dopamine agonists, monoamine oxidase-B inhibitors, and catechol- $O$-methyl transferase inhibitors do not need to be discontinued. They showed no significant effect on the striatal ${ }^{123}$ I-FP-CIT uptake $(28,29)$. However, selective serotonin reuptake inhibitors, which are used to treat depression in PD patients, influence ${ }^{123}$ I-FP-CIT uptake by binding to serotonin transporters (30). Central nervous system stimulants (amphetamine analogs, sympathomimetics including some nasal decongestants) also affect DAT binding, and it is recommended that they be stopped for $4 \mathrm{wk}$ (28). Technical details, including parameters for image acquisition and processing, are well described in the practice guidelines of the Society of Nuclear Medicine and Molecular Imaging and a workbook from GE Healthcare (16,31).

\section{VISUAL INTERPRETATION AND SEMIQUANTITATIVE ANALYSIS}

DAT SPECT results can be easily classified as normal or abnormal by visual interpretation based on the striatal activity. ${ }^{123}$ I-FP-CIT uptake pattern and density in the striatum are examined in terms of the shape of the bilateral striata, symmetry, gradient between the caudate nucleus and the putamen, and the degree of reduction. Normally, the bilateral striata appear as symmetric comma-shaped hot uptake on the imaging. In PD, ${ }^{123}$ I-FP-CIT uptake, in other words DAT density, is usually asymmetric in the left and right striata. The side with relatively lower uptake generally matches contralaterally to the clinically more affected side.
As for anterior-posterior asymmetry, the putamen demonstrates more reduction than the caudate nucleus, and uptake in the dorsal-posterior putamen is more reduced than that in the other parts of the putamen (32). Figure 2 shows ${ }^{123} \mathrm{I}-$ FP-CIT SPECT images of normal and abnormal brain. The semiquantification of DAT density in the striata can be made by calculating the ratio of specific to nonspecific binding using the cerebellum or occipital lobe as a reference region. Striatal DAT density (or striatal binding ratio) is determined by the formula mean counts of striatal region of interest divided by mean counts of a reference region of interest minus 1. For quantifying activities in small structures such as a brain stem area, a PET scan is preferable because of its superior spatial resolution (Fig. 3). Currently, there are no FDA-approved quantitative software packages for calculating the ratio of specific to nonspecific binding, but similar to the evolution of cardiac nuclear medicine, validated software packages approved by the FDA are being developed. It would be helpful to report semiquantitative evaluation results along with descriptive findings.

\section{CLINICAL APPLICATION OF DAT IMAGING}

In clinical practice, DAT imaging assists mainly when there is clinical diagnostic uncertainty between true parkinsonism and other movement disorders (33). Patients may show a subtle and unclear initial presentation, atypical progression, or atypical therapeutic response. One in 5 suspected Parkinsonian syndrome cases remains clinically uncertain (34). Another good indication for DAT imaging might be a potential drug-induced parkinsonism (DIP) case where removing the patient from a drug is difficult (33). One criterion used to diagnose DIP is the discontinuance of a patient's medications to determine whether symptoms improve. However, when, for example, antiepileptic or antipsychotic drugs are suspected to have induced parkinsonism in a patient, it might be more practical to image striatal DAT density than to try to discontinue those drugs. In the same context, DAT imaging is also useful when a levodopa

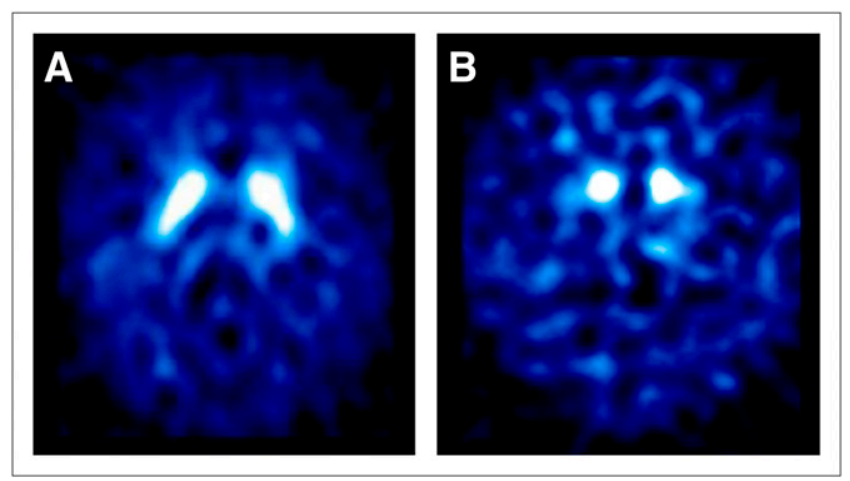

FIGURE 2. Brain ${ }^{123} /$-FP-CIT SPECT images. Transaxial slices at striatal level. (A) Normal ${ }^{123}$ I-FP-CIT uptake, which is often described as comma shaped, is seen in healthy subject. (B) Striatal uptake is decreased in patient with PD. Reduction is more prominent in putamen than in caudate nucleus. 


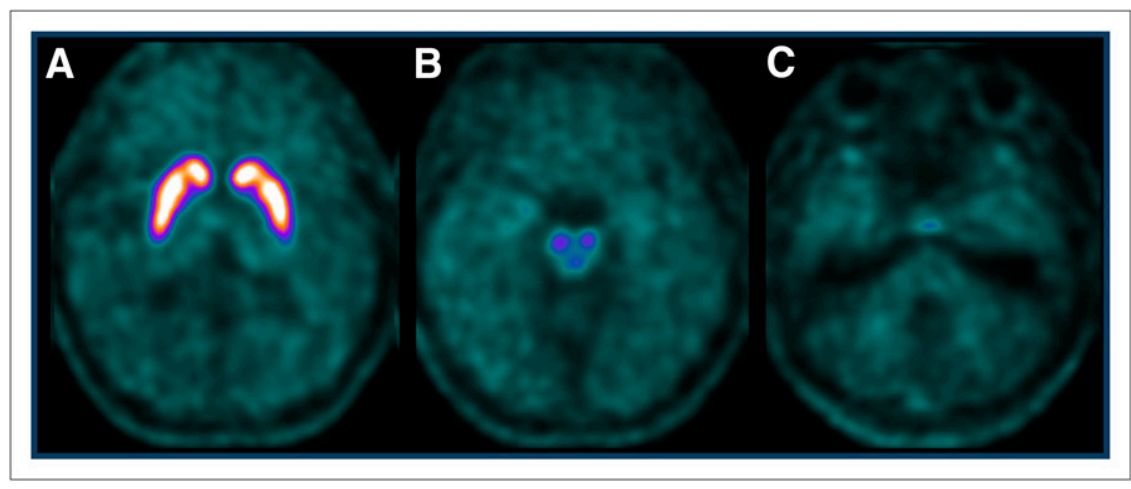

FIGURE 3. Superior spatial resolution of brain ${ }^{18} \mathrm{~F}-\mathrm{FP}-\mathrm{CIT}$ PET images. Superior spatial resolution of brain PET enables us to see caudate nucleus and putamen separately, and to analyze small brain structures such as in brain stem area. Another advantage of ${ }^{18} \mathrm{~F}-\mathrm{FP}-\mathrm{CIT}$ PET is that it can be acquired 2-3 $\mathrm{h}$ after injection.

trial is problematic (33). DAT imaging is not necessary in clinically definite PD patients. DAT imaging is currently not recommended as a stand-alone diagnostic tool (33). It does not help to differentiate PD from atypical Parkinsonian syndrome (APS) (e.g., multiple-system atrophy, progressive supranuclear palsy). Both PD and APS have presynaptic dopaminergic degeneration and demonstrate decreased striatal uptake on DAT imaging. Postsynaptic dopaminergic imaging needs to be added to increase diagnostic accuracy (35). Postsynaptic $\mathrm{D}_{2}$ receptor binding is normal or increased in PD whereas it is decreased in APS (36). ${ }^{18}$ F-FDG PET has been also used to distinguish PD from APS using their different metabolic patterns (37-39). Whether DAT imaging is useful in the assessment of treatment response, monitoring of disease progression, and early diagnosis of PD in the premotor stage is still in its research phase.

\section{DIFFERENTIAL DIAGNOSIS OF PARKINSONISM}

Diagnostic possibilities in parkinsonism or tremor include a variety of diseases (Fig. 4). DIP, which is induced by dopamine receptor antagonist drugs, and essential tremor, which has characteristic kinetic or postural tremor, are 2 of the most common diagnostic errors $(40,41)$. They show normal DAT imaging results, which make it easy to differentiate them from PD (Fig. 5). Parkinsonism can also come from a cerebral infarct. Vascular parkinsonism may occur when there are vascular lesions in the basal ganglia or

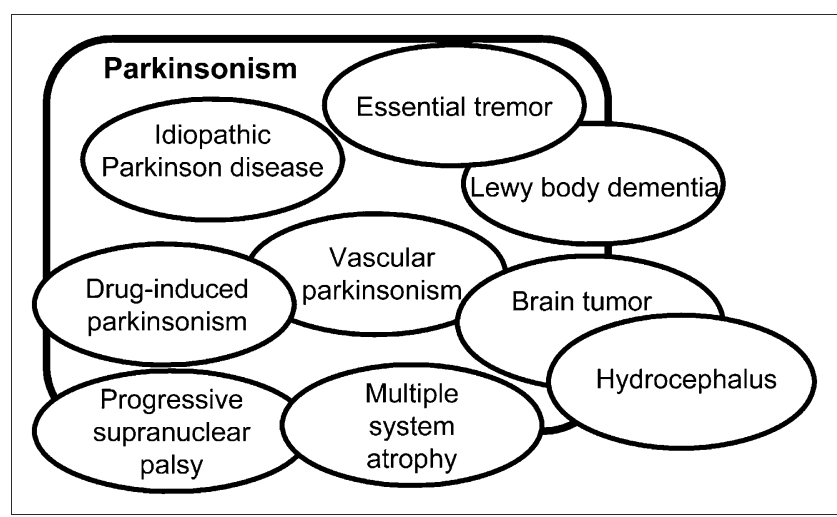

FIGURE 4. Variety of diseases mimicking idiopathic PD. in the subcortical white matter (42). In vascular parkinsonism, DAT imaging shows normal or near-normal results, unless there is focal basal ganglia infarction, which leads to the characteristic punched-out deficit (13). DAT imaging
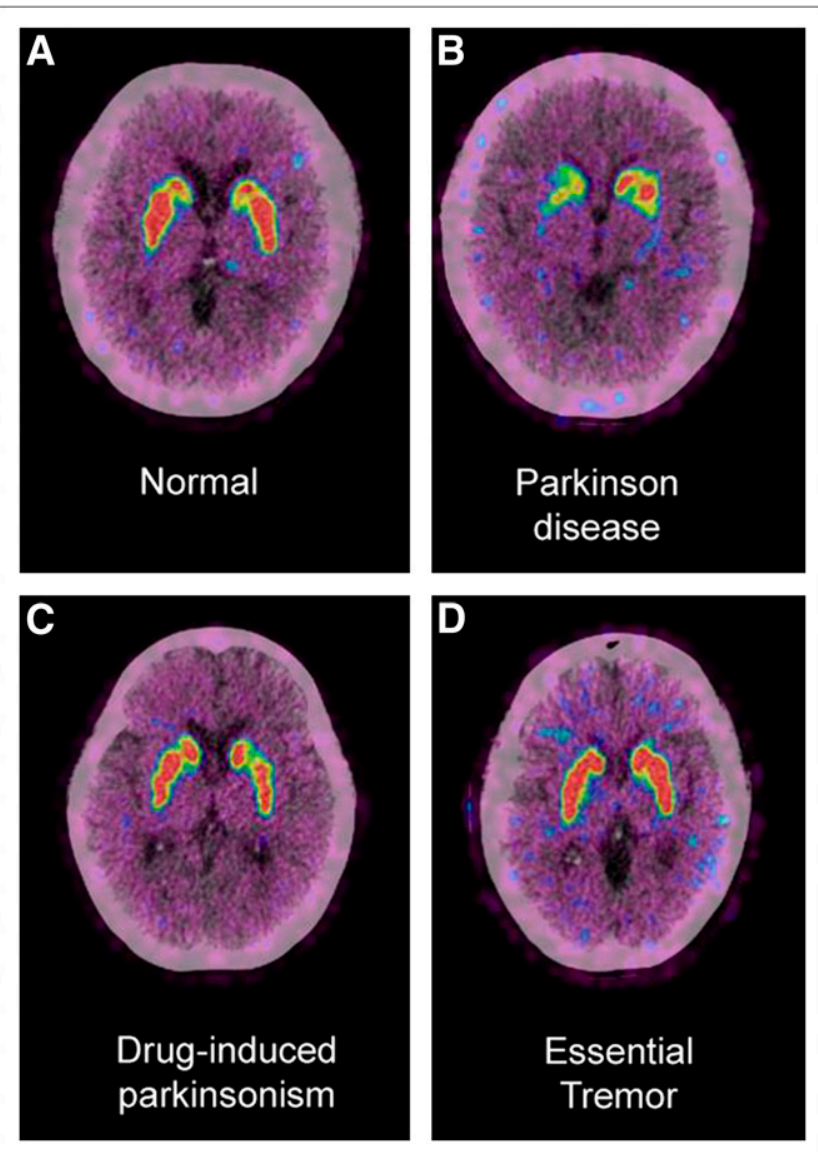

FIGURE 5. Differential diagnosis of parkinsonism using brain ${ }^{18} \mathrm{~F}-\mathrm{FP}-\mathrm{CIT}$ PET. Brain PET/CT images of ${ }^{18} \mathrm{~F}-\mathrm{FP}-\mathrm{CIT}$ uptake at level of striatum demonstrate different DAT density in different conditions. DAT density is decreased in PD patient (B), whereas DAT density is normal in healthy subject $(A)$ and in patients with drug-induced parkinsonism (C) and essential tremor (D). DAT imaging is useful for differential diagnosis of various causes of parkinsonism. Clinical diagnosis of parkinsonism is quite often straightforward, obviating additional tests, but when overlap and incomplete syndromes are present, improvements in diagnostic accuracy may be possible using DAT imaging. 
is also useful to differentiate the cause of dementia. The 2 most common forms of dementia, Alzheimer disease and DLB, share clinical features and are often difficult to differentiate. With DAT imaging, these 2 disorders can be easily distinguished. DLB has dopaminergic degeneration, but Alzheimer disease does not (Fig. 6).

\section{DIAGNOSTIC VALUE OF DAT IMAGING}

Brain CT or MRI is usually performed in the diagnostic work-up of parkinsonism. However, there is no PD-specific finding on those images. Structural imaging modalities are mainly required to rule out secondary forms of parkinsonism (43). DAT imaging enables the in vivo demonstration of striatal dopamine activity (Fig. 7). ${ }^{123}$ I-FP-CIT SPECT has high power to discriminate PD from normal aging, particularly when DAT density in the putamen is evaluated (44). The sensitivity and specificity of ${ }^{123}$ I-FP-CIT SPECT for differentiating essential tremor from PD are reported to be $95 \%$ and $94 \%$, respectively (44). One multicenter study showed that ${ }^{123}$ I-FP-CIT DAT SPECT contributed to a change in diagnosis in $52 \%$ of patients and also prompted changes in the clinical management in $72 \%$ of patients (34).

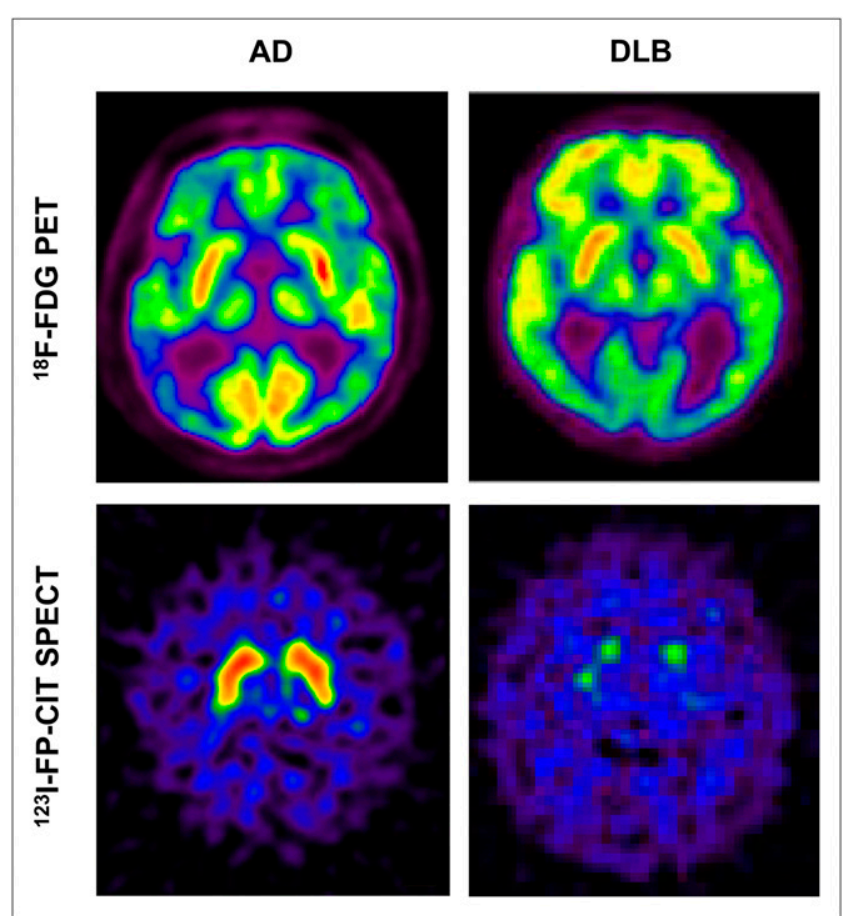

FIGURE 6. Differential diagnosis of dementia using brain ${ }^{123} \mathrm{~F}-$ FP-CIT SPECT. The 2 most common forms of dementia, Alzheimer disease (AD) and DLB, share clinical features and are often difficult to differentiate. ${ }^{18} \mathrm{~F}-\mathrm{FDG}$ PET is useful when typical bilateral temporoparietal hypometabolism is seen in $A D$ and occipital hypometabolism is seen in DLB, as demonstrated in these images; however, that is not always case. With DAT imaging, for example, using ${ }^{123} \mathrm{I}-\mathrm{FP}-\mathrm{CIT}$, these 2 disorders can be more easily distinguished. Striatal dopaminergic deficit occurs in DLB but not in AD.

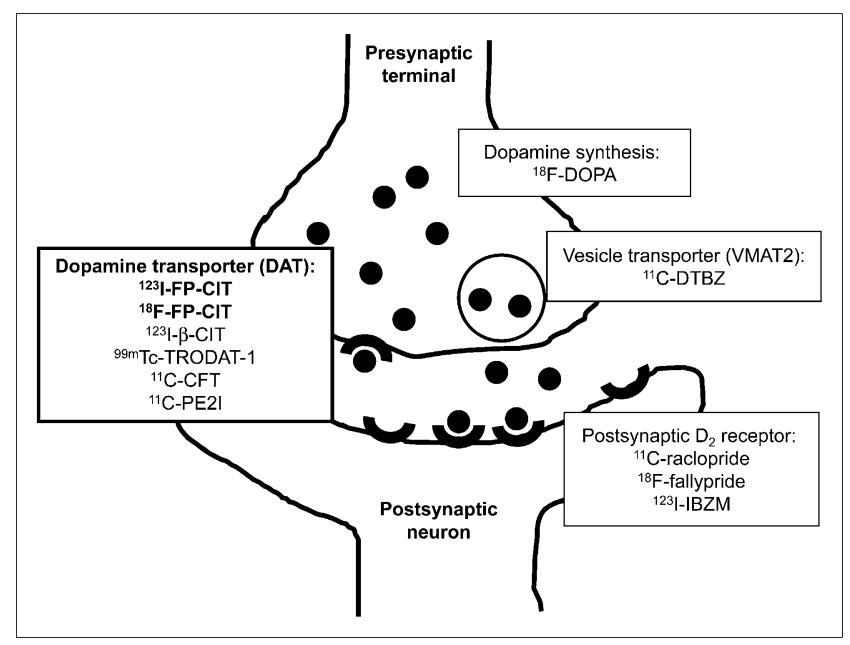

FIGURE 7. Molecular targets for imaging dopamine system. Illustration is of dopamine nerve terminal and examples of several radioligands that enable in vivo demonstration of dopamine synthesis, rerelease into synaptic cleft, uptake by postsynaptic receptors, and active reuptake by DAT, respectively. Each step of dopamine synthesis, release, and reuptake can be imaged and measured with nuclear medicine molecular imaging techniques.

\section{DAT DENSITY AND DISEASE SEVERITY}

The most frequently asked question by most PD patients might be how severe their symptom is and in what stage of disease they are categorized. Evaluating disease severity is important in establishing a proper treatment strategy. The Unified Parkinson Disease Rating Scale and Hoehn and Yahr Scale are the most commonly and most widely used scales to assess the clinical severity of PD. They are also used in research to determine the eligibility of patients to participate in research (45). According to the Hoehn and Yahr Scale, increasing Parkinsonian motor impairment can be charted from unilateral (stage I) to bilateral involvement (stage II) without balance difficulties, to the presence of postural instability (stage III), loss of physical independence (stage IV), and being wheelchair- or bed-bound (stage V) (46). Striatal presynaptic dopaminergic function evaluated by DAT imaging reflects Hoehn and Yahr staging $(32,47)$ and is correlated with the motor Unified Parkinson Disease Rating Scale (32). The reduction of striatal DAT density is more profound in the advanced stages than in the early stages. Nondopaminergic symptoms such as swallowing and speech difficulties, sleep disturbance, constipation, depression, and dementia also matter to the quality of life for PD patients (48). Our nuclear medicine molecular imaging technique is expected to play a key role in investigating nondopaminergic neuronal systems in order to better understand and treat PD.

\section{COST EFFECTIVENESS OF DAT IMAGING}

Although DAT imaging may be expensive, the cost effectiveness of DAT imaging is reported to be good (4951). For example, Van Laere et al. (51) analyzed the cost 
effectiveness of ${ }^{123}$ I-FP-CIT SPECT in patients with inconclusive Parkinsonian features, by working on a complete Belgian registry of 1,701 consecutive patients. They found that the initial diagnosis was changed in $51.5 \%$ of patients, and the management was altered in $49 \%$. However, cost effectiveness may differ from country to country according to each country's health care systems. There is not enough evidence to generalize the cost effectiveness of ${ }^{123}$ I-FP-CIT at the moment.

\section{CONCLUSION}

A new era of DAT imaging has begun with the approval of ${ }^{123}$ I-FP-CIT for clinical use by the FDA. ${ }^{123}$ I-FP-CIT binds to DAT protein and enables reliable visualization of DAT distribution in the striatum. ${ }^{123}$ I-FP-CIT SPECT and SPECT or PET using various other DAT radioligands are useful as diagnostic adjuncts in movement disorders and dementia. They give diagnostic capability to physicians that may lead to timely and appropriate treatments for patients with suspected Parkinsonian syndrome.

\section{ACKNOWLEDGMENTS}

We give special thanks to Eplida S. Crawford, CNMT, clinical associate professor, University at Buffalo, for helpful comments and suggestions on the manuscript. No potential conflict of interest relevant to this article was reported.

\section{REFERENCES}

1. Nussbaum RL, Ellis CE. Alzheimer's disease and Parkinson's disease. $N$ Engl J Med. 2003;348:1356-1364.

2. Parkinson's disease backgrounder. National Institute of Neurological Disorders and Stroke. Available at: www.ninds.nih.gov/disorders/parkinsons_disease/ parkinsons_disease_backgrounder.htm. Accessed October 31, 2012.

3. de Rijk MC, Tzourio C, Breteler MM, et al. Prevalence of parkinsonism and Parkinson's disease in Europe: the EUROPARKINSON Collaborative Study. European Community Concerted Action on the Epidemiology of Parkinson's disease. J Neurol Neurosurg Psychiatry. 1997;62:10-15.

4. NIH fact sheets: Parkinson's disease. National Institutes of Health. Available at: http://report.nih.gov/nihfactsheets/ViewFactSheet.aspx?csid=109. Accessed October 31, 2012.

5. Hoehn MM, Yahr MD. Parkinsonism: onset, progression and mortality. Neurology. 1967; 17:427-442.

6. Benamer HT, Patterson J, Wyper DJ, Hadley DM, Macphee GJ, Grosset DG. Correlation of Parkinson's disease severity and duration with ${ }^{123}$ I-FP-CIT SPECT striatal uptake. Mov Disord. 2000;15:692-698.

7. Eerola J, Tienari PJ, Kaakkola S, Nikkinen P, Launes J. How useful is [ $\left.{ }^{123} I\right]$ betaCIT SPECT in clinical practice? J Neurol Neurosurg Psychiatry. 2005;76:12111216 .

8. Kish SJ, Shannak K, Hornykiewicz O. Uneven pattern of dopamine loss in the striatum of patients with idiopathic Parkinson's disease: pathophysiologic and clinical implications. N Engl J Med. 1988;318:876-880.

9. Jaber M, Jones S, Giros B, Caron MG. The dopamine transporter: a crucial component regulating dopamine transmission. Mov Disord. 1997;12:629-633.

10. Amara SG, Kuhar MJ. Neurotransmitter transporters: recent progress. Annu Rev Neurosci. 1993;16:73-93.

11. Giros B, Caron MG. Molecular characterization of the dopamine transporter. Trends Pharmacol Sci. 1993;14:43-49.

12. FDA approved drug products. U.S. Food and Drug Administration. Available at: http://www.accessdata.fda.gov/scripts/cder/drugsatfda/index.cfm?fuseaction=Search. DrugDetails. Accessed October 31, 2012.

13. Marshall V, Grosset D. Role of dopamine transporter imaging in routine clinical practice. Mov Disord. 2003;18:1415-1423.
14. Andringa G, Drukarch B, Bol JG, et al. Pinhole SPECT imaging of dopamine transporters correlates with dopamine transporter immunohistochemical analysis in the MPTP mouse model of Parkinson's disease. Neuroimage. 2005;26: 1150-1158.

15. Ravina B, Eidelberg D, Ahlskog JE, et al. The role of radiotracer imaging in Parkinson disease. Neurology. 2005;64:208-215.

16. Djang DS, Janssen MJ, Bohnen N, et al. SNM practice guideline for dopamine transporter imaging with ${ }^{123}$ I-ioflupane SPECT 1.0. J Nucl Med. 2012;53:154163.

17. Eshuis SA, Jager PL, Maguire RP, Jonkman S, Dierckx RA, Leenders KL. Direct comparison of FP-CIT SPECT and F-DOPA PET in patients with Parkinson's disease and healthy controls. Eur J Nucl Med Mol Imaging. 2009;36:454462.

18. DaTSCAN (I-123 Ioflupane). European Medicines Agency. Available at: http://www.ema.europa.eu/ema/index.jsp?curl=pages/medicines/human/ medicines/000266/human_med_000739.jsp\&mid=WC0b. Accessed October 31, 2012.

19. Darcourt J, Booij J, Tatsch K, et al. EANM procedure guidelines for brain neurotransmission SPECT using ${ }^{123} \mathrm{I}$-labelled dopamine transporter ligands, version 2. Eur J Nucl Med Mol Imaging. 2010;37:443-450.

20. Committee for New Health Technology Assessment. ${ }^{123}$ I-FP-CIT ( ${ }^{123}$ I-ioflupane) brain single photon emission computed tomography [online database]. Available at: http://nhta.or.kr/nHTA/english/03_report/02_condition_view. jsp? $\mathrm{t}=20121105061143163 \&$ boardNo $=9 \&$ cpage $=1 \&$ seq $=1105$. Accessed October 31, 2012.

21. General Electric Company. DaTSCAN ${ }^{\mathrm{TM}}$ (ioflupane I-123 injection) now available to help physicians assess patients with suspected parkinsonian syndromes. 2012. Available at: http://www.genewscenter.com/content/detail.aspx?ReleaseID= 12752\&NewsAreaID=2. Accessed October 31, 2012.

22. Kung HF, Kung MP, Wey SP, Lin KJ, Yen TC. Clinical acceptance of a molecular imaging agent: a long march with [ $\left.{ }^{99 \mathrm{~m}} \mathrm{Tc}\right] \mathrm{TRODAT}$. Nucl Med Biol. 2007; 34:787-789.

23. Kim JS. Practical approach for the clinical use of dopamine transporter imaging. Nucl Med Mol Imaging. 2008;42:425-434.

24. Lee SJ, Oh SJ, Chi DY, et al. One-step high-radiochemical-yield synthesis of [ ${ }^{18}$ F]FP-CIT using a protic solvent system. Nucl Med Biol. 2007;34:345-351.

25. Abi-Dargham A, Gandelman MS, DeErausquin GA, et al. SPECT imaging of dopamine transporters in human brain with iodine-123-fluoroalkyl analogs of beta-CIT. J Nucl Med. 1996;37:1129-1133.

26. Laruelle M, Wallace E, Seibyl JP, et al. Graphical, kinetic, and equilibrium analyses of in vivo $\left[{ }^{123} \mathrm{I}\right]$ beta-CIT binding to dopamine transporters in healthy human subjects. J Cereb Blood Flow Metab. 1994;14:982-994.

27. Neumeyer JL, Wang S, Gao Y, et al. N-omega-fluoroalkyl analogs of (1R)-2 beta-carbomethoxy-3 beta-(4-iodophenyl)-tropane (beta-CIT): radiotracers for positron emission tomography and single photon emission computed tomography imaging of dopamine transporters. J Med Chem. 1994;37:1558-1561.

28. Booij J, Kemp P. Dopamine transporter imaging with [ ${ }^{123}$ I] FP-CIT SPECT: potential effects of drugs. Eur J Nucl Med Mol Imaging. 2008;35:424-438.

29. Schillaci O, Pierantozzi M, Filippi L, et al. The effect of levodopa therapy on dopamine transporter SPECT imaging with ${ }^{123}$ I-FP-CIT in patients with Parkinson's disease. Eur J Nucl Med Mol Imaging. 2005;32:1452-1456.

30. Booij J, de Jong J, de Bruin K, Knol R, de Win MM, van Eck-Smit BL. Quantification of striatal dopamine transporters with ${ }^{123}$ I-FP-CIT SPECT is influenced by the selective serotonin reuptake inhibitor paroxetine: a double-blind, placebocontrolled, crossover study in healthy control subjects. J Nucl Med. 2007; 48:359-366.

31. Imaging with DaTSCAN: A Workbook. General Electric Company. GE Healthcare. 2006. Available at: http://ksnm.or.kr/upload/journal/420202.pdf. Accessed November 6, 2012.

32. Wang J, Zuo CT, Jiang YP, et al. ${ }^{18} \mathrm{~F}$-FP-CIT PET imaging and SPM analysis of dopamine transporters in Parkinson's disease in various Hoehn \& Yahr stages. J Neurol. 2007;254:185-190.

33. GE Healthcare. DaTSCAN ${ }^{\mathrm{TM}}$ (ioflupane I-123 injection) briefing document: peripheral and central nervous system drugs advisory committee meeting. Available at: http://www.fda.gov/downloads/AdvisoryCommittees/CommitteesMeetingMaterials/ Drugs/PeripheralandCentralNervousSystemDrugsAdvisoryCommittee/UCM186404. pdf. Accessed October 31, 2012.

34. Catafau AM, Tolosa E. Impact of dopamine transporter SPECT using ${ }^{123}{ }^{2}$-ioflupane on diagnosis and management of patients with clinically uncertain Parkinsonian syndromes. Mov Disord. 2004;19:1175-1182.

35. Mo SJ, Linder J, Forsgren L, Larsson A, Johansson L, Riklund K. Pre- and postsynaptic dopamine SPECT in the early phase of idiopathic parkinsonism: a population-based study. Eur J Nucl Med Mol Imaging. 2010;37:21542164 . 
36. Nikolaus S, Antke C, Muller HW. In vivo imaging of synaptic function in the central nervous system: I. Movement disorders and dementia. Behav Brain Res. 2009;204:1-31.

37. Eckert T, Tang C, Ma Y, et al. Abnormal metabolic networks in atypical parkinsonism. Mov Disord. 2008;23:727-733.

38. Juh R, Kim J, Moon D, Choe B, Suh T. Different metabolic patterns analysis of Parkinsonism on the ${ }^{18}$ F-FDG PET. Eur J Radiol. 2004;51:223-233.

39. Kwon KY, Choi CG, Kim JS, Lee MC, Chung SJ. Diagnostic value of brain MRI and ${ }^{18}$ F-FDG PET in the differentiation of Parkinsonian-type multiple system atrophy from Parkinson's disease. Eur J Neurol. 2008;15:1043-1049.

40. Meara J, Bhowmick BK, Hobson P. Accuracy of diagnosis in patients with presumed Parkinson's disease. Age Ageing. 1999;28:99-102.

41. Quinn N. Parkinsonism: recognition and differential diagnosis. BMJ. 1995; 310:447-452.

42. Kim JM, Kim YK, Kim SE, Jeon BS. Clinical usefulness of dopamine transporter imaging. Nucl Med Mol Imaging. 2007;41:152-157.

43. Koller W, Minagan A. Treatment strategies for the management of Parkinson's disease. In: Parkinson's Disease Management Guide. Montvale, NJ: Medical Economics Company Inc.; 2001:101-133.

44. Varrone A, Halldin C. Molecular imaging of the dopamine transporter. $\mathrm{J} \mathrm{Nucl}$ Med. 2010;51:1331-1334.
45. PD screening instruments and scales. National Parkinson Foundation. Available at: http://www.parkinson.org/Professionals/Professional-Resources/ScreeningInstruments.aspx. Accessed October 31, 2012.

46. Goetz CG, Poewe W, Rascol O, et al. Movement Disorder Society Task Force report on the Hoehn and Yahr staging scale: status and recommendations. Mov Disord. 2004;19:1020-1028.

47. Staffen W, Mair A, Unterrainer J, Trinka E, Ladurner G. Measuring the progression of idiopathic Parkinson's disease with [ $\left.{ }^{123} \mathrm{I}\right]$ beta-CIT SPECT. J Neural Transm. 2000;107:543-552.

48. Obeso JA, Rodriguez-Oroz MC, Goetz CG, et al. Missing pieces in the Parkinson's disease puzzle. Nat Med. 2010;16:653-661.

49. Antonini A, Berto P, Lopatriello S, Tamma F, Annemans L, Chambers M. Costeffectiveness of ${ }^{123}$ I-FP-CIT SPECT in the differential diagnosis of essential tremor and Parkinson's disease in Italy. Mov Disord. 2008;23:2202-2209.

50. Dodel RC, Hoffken H, Moller JC, et al. Dopamine transporter imaging and SPECT in diagnostic work-up of Parkinson's disease: a decision-analytic approach. Mov Disord. 2003;18(suppl 7):S52-S62.

51. Van Laere K, Everaert L, Annemans L, Gonce M, Vandenberghe W, Vander Borght T. The cost effectiveness of ${ }^{123}$ I-FP-CIT SPECT imaging in patients with an uncertain clinical diagnosis of parkinsonism. Eur J Nucl Med Mol Imaging. 2008;35:1367-1376. 